\title{
Renewable energy policy landscape in South Africa: moving towards a low carbon economy
}

\author{
G. Nhamo \& S.-Y. Ho \\ University of South Africa, South Africa
}

\begin{abstract}
The South African agenda for renewable energy policy is linked to a target of $10,000 \mathrm{GWh}$ by 2013 . This is a vision put in place in order to mitigate negative impacts of climate change, address the energy mix and move towards a low carbon economy. The Ernst \& Young 'All Renewables Index' ranked South Africa $27^{\text {th }}$ out of the 30 countries included in the index. This paper documents policy developments within South Africa's renewable energy space. The paper considers the policy landscape at various levels namely: acts of parliament, policies (white papers) and green papers, strategies and action plans as well as regulations and instruments. We conclude that South Africa has moved swiftly to establish an effective legislative regime for renewable energy investment and this is assisting the country in fulfilling its vision as outlined earlier.
\end{abstract}

Keywords: South Africa, renewable energy, low carbon economy.

\section{Introduction}

The primary energy mix as determined from the National Energy Efficiency Strategy of 2009 shows that renewable energy accounted for $9 \%$ of the energy mix in South Africa in 2004 DME [1]. Coal and crude oil contributed 67\% and $18 \%$ of the energy mix respectively. Following the United Nations Framework Convention on Climate Change (UNFCCC) conference that took place in Copenhagen in 2009, South Africa pledged to reduce emissions. The pledge has a strong bearing in terms of promoting investment in renewable energy. The country pledged to undertake mitigation actions resulting in deviation below the current emissions baseline of $34 \%$ by 2020 and $42 \%$ by 2025 . The pledge was conditional on a fair, ambitious and effective global climate deal being reached 
and financial, technology and capacity building support from the developed countries (The Presidency [2]). During the apartheid era, from 1948 up to 1993 energy policies were centred on energy security, with a concentration on the exploitation of coal reserves by state owned companies, Eskom and Sasol. Eskom deals with electricity and Sasol synthetic fuel and natural gas. However, the energy policy has undergone substantial revisions since 1994 with targets spelt out in relation to job creation and economic security and sustainable development (Prasad and Visagie [3]).

Figure 1 presents a picture with regards to a frequency count in terms of renewable energy as featured in selected key government policies. Among the policies reviewed are: the National Climate Response Green Paper (NCCRGP), Draft Carbon Tax Option (DCTO), Industrial Policy Action Plan II (IPAP II), Draft Integrated Resources Plan (DIRP), South African Renewables Initiative (SARI), Western Cape Government Green Procurement Policy (WCGGPP), National Energy Act (NEA), Long Term Mitigation Scenario (LTMS), revised National Energy Efficiency Strategy (NEES), Energy Efficiency Accord (EEA), White Paper on Energy Policy (WPEP), White Paper on Renewable Energy (WPRE) and the Carbon Disclosure Project South Africa (CDP SA). Figure 1 makes it clear that the White Paper on Renewable Energy (WPRE) of 2003 is the main reference document.

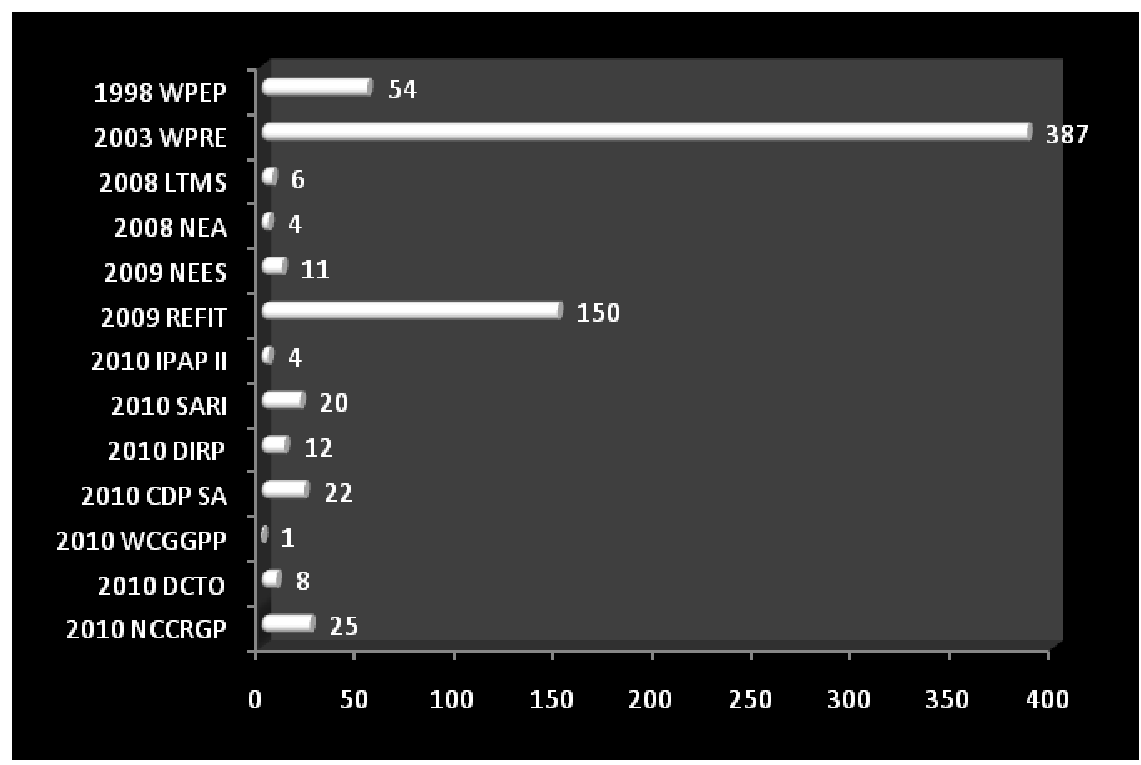

Source: Authors

Figure 1: Renewable energy in key SA policy and industry initiatives. 


\section{Renewable energy: an international perspective}

Bordier [4] maintains that the EU policy for renewable energy and climate change is based on two directives: "the 2001 European directive with the objective to increase the share of electricity generated from renewable energy sources to $21 \%$ by 2010 in the EU-25" and "the 2003 directive establishing the European Union Emissions Trading Scheme (EU ETS) that entered into effect in 2005 imposing a cap on carbon dioxide emissions for the high-emitting European sectors". The cost of renewable energy technologies is, however, noted as a major obstacle to developments in this space.

To promote investment in renewable energy a range of incentives exist across the EU including: calls for tenders, feed-in tariffs and green certificates. The consumption of renewable energy by the top 10 countries in the EU in 2005 (and targets to 2020) is ranked as follows Bordier [4]: Sweden - 39.8\% (49\%), Latvia $-34 \%$ (42\%), Finland - 28.5\% (38\%), Austria - 23.3\% (34\%), Portugal - 20.5\% (31\%), Estonia - 18\% (25\%), Romania - 17.8\% (24\%), Denmark - 17\% (30\%), Slovenia - 16\% (25\%) and Lithuania - 15\% (23\%). A Renewable Energy Index regularly surveyed globally by Ernst \& Young gives further details regarding investment in this sector. Among the top five countries are China, USA, Germany, India and UK (Ernst and Young [5]). Further details regarding selected countries are shown in Table 1 . The various indices are scored out of 100 points.

Table 1: $\quad$ Renewables energy index (November 2010).

\begin{tabular}{|c|c|c|c|c|c|c|}
\hline Country (Rank) & All & Wind & Solar & $\begin{array}{c}\text { Biomass/ } \\
\text { Other }\end{array}$ & $\begin{array}{c}\text { Geo- } \\
\text { thermal }\end{array}$ & $\begin{array}{c}\text { Infra- } \\
\text { structure }\end{array}$ \\
\hline China (1) & 71 & 76 & 60 & 58 & 51 & 76 \\
\hline USA (2) & 66 & 66 & 72 & 61 & 67 & 60 \\
\hline Germany (3) & 63 & 66 & 54 & 63 & 54 & 62 \\
\hline India (4) & 63 & 64 & 67 & 58 & 45 & 65 \\
\hline UK (5) & 62 & 68 & 40 & 59 & 38 & 71 \\
\hline Brazil (18) & 46 & 47 & 41 & 49 & 22 & 46 \\
\hline S/Korea (18) & 46 & 47 & 46 & 41 & 35 & 43 \\
\hline Egypt (22) & 43 & 44 & 48 & 37 & 27 & 40 \\
\hline Mexico (25) & 42 & 43 & 45 & 38 & 57 & 38 \\
\hline S/Africa (27) & 41 & 43 & 37 & 35 & 32 & 43 \\
\hline
\end{tabular}

Source: Authors, based on Ernst andYoung [5].

A Carbon Disclosure Project (CDP) 2010 report on Corporate Clean Energy Investment Trends in Brazil, China, India and South Africa (BASIC) revealed four key findings: that there are sizeable investments in clean energy, there was need for high-level policy signals, need for clear and specific regulation and that the Kyoto Protocol's Clean Development Mechanism (CDM) had made a significant contribution CDP [6]. 


\section{Acts of Parliament}

The National Energy Act of 2008 is central when dealing with renewable energy in South Africa. Reference to renewable energy features in Section 19 dealing with regulations. Section 19 (1) (d) makes provision for the promulgation of regulations addressing the minimum contributions to the national energy supply from renewable energy sources RSA [7]. Section 19 (1) (e) makes provision for the proclamation of regulations specifying the nature of the sources that may be used for renewable energy contributions to the national energy supply. Section 19 (1) (f) makes provision for the establishment of regulations regarding measures and incentives designed to promote the production, consumption, investment, research and development of renewable energy.

\section{Policies (white papers) and green papers}

\subsection{Energy white paper for South Africa - 1998}

The fifth objective of the White Paper addresses the need to provide alternative sources of energy including renewable energy DME [8]. Renewable energy is identified among seven energy supply sectors including electricity, nuclear energy, oil and gas, liquid fuels, gas and coal. The government indicated that it was interested facilitating "sustainable production and management of solar power and non-grid electrification systems, such as the further development of home solar systems, solar cookers, solar pump water supply systems, solar systems for schools and clinics, solar heating systems for homes, hybrid electrification systems and wind power" [8]. Government also identified hydro from the Cahora Bassa in Mozambique and other similar options in Africa.

The White Paper DME [8] revealed that government would promote the use of appropriate standards, guidelines and codes of practice for renewable energy. Suitable renewable energy information systems would have to be put in place. The use of an environmental levy on energy sales that would be used to fund the development of renewable energy was to be investigated. By the time of completing the White Paper, renewable energy resources provided an estimated $10 \%$ of the country's primary energy DME [8]. Although more than $484,000 \mathrm{~m}^{2}$ of solar water heater panels had been installed in the country then, the figure only accounted for less than $1 \%$ of the potential market. The installed capacity of photovoltaic systems was an estimated $5 \mathrm{MW}$ peak, of which $50 \%$ is used for telecommunications. About 280,000 water-pumping windmills were operational with installed capacity of small-scale hydro in excess of $60 \mathrm{MW}$.

Renewable energy was noted as being advantageous in that it has minimal environmental impacts in comparison with traditional supply technologies, has generally lower running costs and high labour intensities. Disadvantages, however, included: higher capital costs, lower energy densities, and lower levels of availability. The government's policy on renewable energy would be concerned with DME [8]: "ensuring that economically feasible technologies and applications are implemented; ensuring that an equitable level of national 
resources is invested in renewable technologies, given their potential and compared to investments in other energy supply options; and addressing constraints on the development of the renewable industry".

\subsection{White paper on renewable energy policy -2003}

The White Paper considers integrated resource planning as the basis for "ensuring that an equitable level of national resources is invested in renewable technologies, given their potential and compared to investments in other energy supply options DME [9]. The White Paper spelt out a target of 10,000GWh by 2013. The target is to be achieved mainly through investments in biomass, wind, solar and small-scale hydro. The $10,000 \mathrm{GWh}$ is approximately $4 \%$ of the projected electricity demand by 2013 . This target is cumulative, starting in 2003 , and so equivalent to an average of $100 \mathrm{GWh} /$ year DME [1]. South Africa has made little progress towards achieving this target in the first half of the period. As of $20093 \%$ (296GWh) of the 10,000 GWh had been installed DME [1]. The White Paper supplements the White Paper on Energy Policy of 1998 four key strategic areas are addressed with their goals spelt out. These include DME [10]: (1) Financial instruments - with the goal to promote the implementation of sustainable renewable energy through the establishment of appropriate financial and fiscal instruments, (2) legal instruments - with a goal to develop, implement, maintain and continuously improve an effective legislative system to promote the implementation of renewable energy, (3) technology development - with a goal to promote, enhance and develop technologies for the implementation of sustainable renewable energy, and (4) awareness raising, capacity building and education-with a goal to raise public awareness of the benefits and opportunities of renewable energy. Each of the goals is accompanied by specific objectives and deliverables.

Multiple players could now enter the generation market through the provisions of the White Paper. This would be done by the responsible authority that would license producers with more than $5 \mathrm{GWh}$ per year, transmitters, distributors and sellers of electricity. The introduction of renewable energy generators would be regulated on a phased approach with the Central Energy Fund providing assistance in the implementation of renewable energy through the extension of its operational support. In addition, The Gas Act and the amended Petroleum Products Act would provide a basis for the integration of renewable energy derived from bio-diesel, ethanol and landfill gas. At the time of finalising the White Paper, the Minister of Finance had announced a 30\% tax reduction for bio-diesel. Notice is taken of a range of barriers to the smooth implementation of renewable energy that requires attention from government and other key players. Some of the barriers include: the high cost of renewable energy technologies; lack of consumer awareness on benefits and opportunities of renewable energy; legal, regulatory and organisational concerns; and a lack of non-discriminatory open access to key energy infrastructure such as the national electricity grid, certain liquid fuels and gas infrastructure DME [10].

Lastly, the White Paper proposed the establishment of technology support centres within existing research and development institutes as well as a proposal 
for a National Energy Research Institute DME [10]. These would facilitate the promotion and ongoing development of technologies and help government in the certification and approval of systems. Cross cutting issues including Integrated Energy Planning, energy efficiency and environmental health are also discussed.

\subsection{National climate change green paper -2010}

The Green Paper DEA [11] considers the impact that renewable energy technologies could have on reducing South Africa's emissions. From a historical perspective, the low cost of electricity made it difficult to incentivise renewable energy investment. However, the Green Paper notes that the announcement of the renewable energy feed-in tariff (REFIT) as well as the electricity generation levy on non-renewable electricity has incentivised investment in wind, solar, hydro and biomass energy. The green jobs creation potential from renewable energy investment is also noted.

In the long term, the Concentrated Solar Power options is viewed as having excellent potential to provide base load and take up a greater share of the energy supply mix. Solar water heaters and photovoltaic cells are well developed globally and these were noted to be generally readily available in the country. The Green Paper makes reference to the $10,000 \mathrm{GWh}$ of renewable energy by 2013 DEA [11]. To contribute towards achieving the target the Green Paper proposes rapid implementation of the renewable energy support mechanisms including the REFIT NERSA [12], the CDM projects, Renewable Energy Certificates, Solar Water Heating subsidies and other financial support mechanisms. Solar Water Heating subsidies are already in place and being supported by government at a significant proportion through the Industrial Policy Action Plan II (IPAP II) DTI [13].

The need to identify and resolve the financial, regulatory and institutional barriers that slow down the implementation of the REFIT at a level adequate to incentivise large-scale investment is called upon DEA [11]. Another call made is in line with a need to review and scale up the 10,000 GWh 2013 renewable energy target. This is said to have the potential to sustain long term growth that will promote competitiveness for renewable energy with conventional energies in the medium and long term. The scaling-up and acceleration of initiatives, such as the Working for Energy Programme (WFEP) under government's Expanded Works Programme is further highlighted. The WFEP has an added advantage in that it increases chances of green jobs creation. Renewable energy project activities that are labour intensive include DEA [11]: biomass from the clearing of invasive alien plants and bush encroachment; biogas for rural energy access; biogas generation from farm waste and municipal solid waste and wastewater; bio fuels development and implementation in rural applications; solar thermal energy like solar geyser fabrication, small scale co-generation; mini-grid hybrid systems and mini-hydro systems for both on and off grid applications". The Green Paper further calls for the development of renewable energy policy, legal and regulatory frameworks that allow for differentiated but specific targets, parameters and tariffs for all renewable energy technology options. This is an element being partially addressed through energy efficiency strategy DME [1]. 
The DEA [11] also calls for the introduction of innovative approaches that will lead to the establishment of sustainable structures and financing mechanisms for delivering renewable energy. This includes securing adequate funding from international climate funding institution and other development finance institutions. The promotion of the development and implementation of appropriate standards and guidelines as well as codes of practice for the appropriate use of renewable energy and low carbon technologies is also hinted upon.

\subsection{Carbon tax option - 2010}

The Carbon Tax Option makes reference to the fact that government has already put in place a range of excise taxes and incentives to support the transition to low-carbon economy. The electricity levy of 2c/kWh implemented in July 2009 National Treasury [14] is one huge step towards developing a comprehensive carbon pricing regime. Tax incentives targeted at government programmes for renewable energy form part of policy response to climate change. Income tax exemptions for income earned from the CDM projects, and accelerated depreciation allowances for investments in biofuels and renewable energy are a series of incentives to encourage investment in these sectors. Reference is also made to the initiatives by the Department of Energy regarding tradable renewable energy certificate scheme, subsidy scheme for investments in renewable energy and energy efficiency and the National Energy Regulator of South Africa in terms of the REFIT.

\section{Strategies and action plans}

\subsection{Biofuels industrial strategy $-\mathbf{2 0 0 7}$}

The Biofuels Strategy indicates that 400 million litres required annually can be produced on $1.4 \%$ of new and existing arable land, with about $14 \%$ of arable land mainly in the former homelands DME [15]. To mitigate against severe droughts and crop failures, the Biofuels Strategy proposed that a certain percentage of feedstock on the additional agricultural land could be redirected to the food market to address shortages. The Strategy proposes sugar cane and sugar beet for bioethanol production through sunflower, canola and soya beans for biodiesel. Maize and Jatropha are currently not utilised for biofuels production given that this might result in food insecurity concerns DME [15]. Before the contestations regarding the use of maize as feedstock, the Free State Biofuels Logistics Hub was established on the assumption that maize would be used. Following extensive research and consideration, The Presidency [16] reported that Cabinet had approved the National Biofuels Strategy in December 2007 and this excluded the use of maize owing to food security concerns. 


\subsection{Industrial policy action plan II $-\mathbf{2 0 1 0}$}

The Industrial Policy Action Plan II (IPAP II) makes reference to the Renewable Energy White Paper's goal of a 10,000 GWh of renewable energy by 2013 DTI [13]. In this regards, the Minister of Energy's initiative to install one million solar water heaters (SWHs) by 2014 is acknowledged with the IPAP II support. The DTI [13] took note of the pending scaling-up of the goal to increase the SWHs 5.6 million by 2020. The DTI also notes that concentrated solar power (CST) is the most promising renewable energy generation option in the country and that this should receive priority support ahead of wind and biomass. The Industrial Development Corporation's CST demonstration plant which aims to leverage the National Energy Regulator of South Africa's REFIT is noted. From the DTI's perspective, the successful demonstration of the viability of the CST pilot plant will lead to a broader rollout of the technology. The DTI also discusses the biofuel sector and concludes that this has grown rapidly globally yet it has remained on the periphery in the country. Several reasons are presented for the slow growth of the biofuels sector in South Africa including: regulatory barriers, global economic crisis and the resultant reduction in oil prices and the national debates that tend to focus on the food versus fuel arguments.

\subsection{Integrated resources plan for electricity: 2010-2030}

The Integrated Resources Plan (IRP) covering the period 2010-2030 DoE [17] links into the REFIT regulations of 2009. The proposed IRP 2010 plan includes Phase 1 of the Renewable Energy power purchase programme that is linked to the REFIT programme amounting to $1025 \mathrm{MW}$. This amount comprises wind, concentrated solar power, landfill and small hydro options (Ibid). Phase 1 of the Medium Term Power Purchase programme of 390 MW consists of cogeneration and own build options. On the other side there is the Open Cycle Gas Turbine (OCGT) Independent Power Producer (IPP) programme of the DoE that is considering generating $1020 \mathrm{MW}$. The nuclear fleet strategy to commence in 2023 will contribute at least $9,6 \mathrm{GW}$ by 2030 . The wind programme outside the REFIT wind capacity commencing in 2014 will contribute a minimum of 3,8 GW with a solar programme outside the REFIT solar capacity commencing in 2016 contributing a minimum $400 \mathrm{MW}$. This also excludes solar water heating that is part of the demand side management (DSM) programme. The renewable programme earmarked to commence 2020 integrating all renewable options will add another 7.2 GW. The IRP DoE [17] also takes note of the imported hydro options (that first emerged in the Energy White Paper of 1998 as discussed) that could total 3349 MW from 2020 to 2023.

The IRP considers environmental and other externality impacts and the effect of renewable energy technologies DoE [17]. To this end, significant investment in wind is encouraged. The approach will ensure a steady and consistent build up in wind capacity to facilitate the stimulation of localisation of manufacturing and green jobs creation. Local experience will be developed in the area of CSP although this technology is expensive. Although the renewable energy options will continue after 2020 these are not specified as per technology type in the IRP 
as such choices will be made when there is more local knowledge and experience with both wind and solar energy. The nuclear option is planned as a base-load option from 2023 and no decision has been made in the IRP regarding this. The IRP notes the delay in the finalisation of the REFIT and other renewable energy options procurement process. The IRP notes that the government is already late in meeting the expectations for wind, small hydro and landfill energy.

\subsection{South African renewables initiative - 2010}

The South African Renewables Initiative (SARI) is a South Africa's Low Carbon Industrial and Economic Strategy to be run jointly by the Departments of Public Enterprise and DTI [18]. SARI is to finance REFIT at a level speed needed to enable a rapid increase in renewables. From the proposal, the REFIT would be financed from a combination of four possible sources namely: domestic electricity consumers, a carbon levy that is currently at 2 cents/kwh, green purchase obligation by major energy and carbon-intensive exporters, and international public finance to be sourced from developed countries with a climate financing commitment as well as interests in bringing its own energy companies into joint industrial ventures in South Africa. The SARI identifies South Africa's greatest renewables opportunity (excluding nuclear) as solar thermal, particularly in the northern parts of the country. It is projected that the country is capable of generating $15 \%$ of its electricity from a combination of wind and solar power by 2020. SARI notes with concern that South Africa has not been able to engage aggressively in transforming the energy mix towards renewables. This is partly due to high cost renewables versus low cost coal. With the REFIT, that stood at about $\mathrm{R} 1 / \mathrm{kwh}$ (with variations depending on technology), which is considered reasonable for concentrated solar power and high for solar photovoltaics, the country was on the road to scale up investments in renewables DoPE and DTI [18].

\section{Regulations}

The REFIT regulations of 2009 stand out as the key regulatory framework to facilitate investment in renewable energy in South Africa. For this reason, this section focuses solely on this regulatory provision. The REFIT is defined in the regulations as "a mechanism to promote the deployment of renewable energy that places an obligation on specific entities to purchase the output from qualifying renewable energy generators at pre-determined prices" NERSA [12]. The REFIT identifies solar, wind, biomas, biofuels, hydropower, wave, tidal, ocean current and geothermal energy as part of the renewable energy supply sources. The REFT takes note of the fast growing renewable energy sector globally. The NERSA [12] mentions that installed global wind capacity early 2008 was $90 \mathrm{GW}$, having doubled since 2004 . China and India were each adding installed wind electricity in excess of $1 \mathrm{GW}$ annually with targets of achieving over $10 \mathrm{GW}$ by 2015 . The capacity of grid connected solar PV was also noted to have quadrupled from an installed capacity of $2 \mathrm{GW}$ in 2004 to about $8 \mathrm{GW}$ at the 
end of 2007 NERSA [12]. More than 58 countries globally were realised to have put in place targets for the promotion of renewable energy and 13 were from developing economies. In terms of employment, the renewable energy industry was noted to be employing over 2.5 million people worldwide. Renewable energy market capitalisation of publicly traded renewables companies had doubled from $\$ 50$ billion to $\$ 100$ billion between 2005 and 2007.

The REFIT also makes reference to South Africa's renewable energy target of $10,000 \mathrm{GWh}$ by 2013. The specific objectives and key principles of the REFIT are to NERSA [12]: create an enabling environment for renewable electricity power generation in South Africa; establish a guaranteed price for electricity generated from renewables for a fixed period of time that provides a stable income stream and an adequate return on investment; create a dynamic mechanism that reflects market, economic and political developments; provide access to the grid and an obligation to purchase power generated; establish an equal playing field with conventional electricity generation; and create a critical mass of renewable energy investment and support the establishment of a self sustaining market. The REFIT makes provision for the establishment of the Eskom Single Buyer Office as the Renewable Energy Purchasing Agency (REPA). This is in line with the provisions of the Electricity Regulation Act of 2006. Qualifying Renewable Energy Power Generators are considered as new investments in electricity generation using technologies including: landfill gas power plant; small hydro power plant (less than $10 \mathrm{MW}$ ); wind power plant and Concentrating Solar Power (CSP) plant. All the REPGs require a Generation Licence issued by NERSA under the Electricity Regulation Act 2006. The conditions for licensing are laid out in the REFIT.

\section{Challenges and achievements in SA renewable energy}

Issues of definitions in government legislation are of concern. In many cases a number of definitions emerge that make implementation difficult. This section looks into definitions from selected legislation. Renewable energy is defined by the White Paper on Renewable Energy Policy DME [10] as energy that "harnesses naturally occurring non-depletable sources of energy, such as solar, wind, biomass, hydro, tidal, wave, ocean current and geothermal, to produce electricity, gaseous and liquid fuels, heat or a combination of these energy types". This is the definition that is used in the REFIT regulations NERSA [12]. The National Energy Act RSA [7] defines renewable energy as "energy generated from natural non-depleting resources including solar energy, wind energy, biomass energy, biological waste energy, hydro energy, geothermal energy and ocean and tidal energy". Already there is divergence in definitions.

Sebitosi and Pillay [19] highlighted the lack of a framework to deliver reliable and accurate energy data to policy makers as a key barrier to faster transformation in the renewable energy sector space in South Africa. In addition, the authors lambasted the dominance of the government power utility ESKOM's in the energy sector. The power utility was accused of operating in an opaque way leading to a black out in terms of data and other necessary key information 
on energy. The changing international scene that was demanding that countries with a high carbon footprint like South Africa 'do something' in terms of renewable energy was also noted a pressing factor moving forward.

Judging by the number of CDM projects in South Africa, renewable energy has taken up a significant portion. As of 20 December 2010, out of the 140 CDM projects submitted for consideration to the South African Designated National Authority and approval by the CDM Board, 26 were for renewable energy and in second place was energy efficiency with 22 projects DoE [20].

\section{Conclusion}

What emerges from this paper is that the renewable energy interface simultaneously addresses climate change, industrial policy and energy issues. In order to promote renewables in South Africa, there is need for high-level policy signals and clear regulation. The REFIT generation incentives are viewed as crucial and South Africa is viewed as being in an advantageous position with regards to solar and wind. The South African agenda for renewable energy policy is linked to a target of 10,000GWh by 2013 spelt of in the White Paper on Renewable Energy Policy of 2003 but little progress has been made towards achieving this target with only $3 \%(296 \mathrm{GWh})$ of the $10,000 \mathrm{GWh}$ having been installed in 2009. One of the major developments from the White Paper on Renewable Energy Policy of 2003 is that it opened up entry of multiple players into the generation market. The National Climate Change Green Paper notes that the announcement of the REFIT as well as the electricity generation levy on nonrenewable electricity has incentivised investment in wind, solar, hydro and biomass energy. A call has been made to review and scale up the 10,000 GWh 2013 renewable energy target.

\section{Acknowledgement}

The authors thank Exxaro Resources Limited for sponsoring the Chair in Business and Climate Change run under Unisa's Institute for Corporate Citizenship.

\section{References}

[1] DME. National Energy Efficiency Strategy of the Republic of South Africa. Pretoria: Department of Minerals and Energy; 2009.

[2] The Presidency. President Jacob Zuma to attend High Level Segment of the COP-15 scheduled for 18 December 2009 in Copenhagen. The Presidency 2009, http://www.thepresidency.gov.za/show.asp?include=president/pr/2009/pr12 081345.htm\&ID=1933\&type $=$ pr.

[3] Prasad G, Visagie E. Renewable energy technologies for poverty alleviation in South Africa. Cape Town: Energy Research Centre; 2005. 
[4] Bordier C. Development of renewable energies: What contribution from the carbon market? Saint-Germain: Caisse des Depots; 2008.

[5] Ernst \& Young. Renewable energy country attractiveness indices. London: Ernest \& Young; 2010.

[6] CDP. Corporate clean energy investment trends in Brazil, China, India and South Africa. London: Carbon Disclosure Project; 2010.

[7] RSA. National Energy Act (No. 34 of 2008). Cape Town: Government Printers, 2008.

[8] DME. White Paper on the Energy Policy of the Republic of South Africa. Pretoria: Department of Minerals and Energy; 1998.

[9] DME. Energy Efficiency Strategy of the Republic of South Africa. Pretoria: Department of Minerals and Energy; 2005.

[10] DME. White Paper on Renewable Energy. Pretoria: Department of Minerals and Energy; 2003.

[11] DEA. National Climate Change Response Green Paper 2010. Pretoria: Department of Environmental Affairs; 2010.

[12] NERSA. South Africa Renewable Energy Feed-in Tariff (REFIT) Regulatory guidelines. Pretoria: National Energy Regulator of South Africa; 2009.

[13] DTI. The 2010/11 - 2012/13 Industrial Policy Action Plan (IPAP II). Pretoria: Department of Trade and Industry; 2010.

[14] National Treasury. Reducing Greenhouse Gas Emissions: The Carbon Tax Option. Pretoria: National Treasury; 2010.

[15] DME. Biofuels Industrial Strategy of the Republic of South Africa. Pretoria: Department of Minerals and Energy; 2007.

[16] The Presidency. ASGISA Annual Report 2007. Johannesburg: The Presidency; 2007.

[17] DoE. Draft Integrated Resources Plan for Electricity for South Africa 2010-2030. Pretoria: Department of Minerals and Energy; 2010.

[18] DoPE, DTI. The South African Renewables Initiative: Advancing South Africa's Low Carbon Industrial and Economic Strategy. Pretoria: Department of Public Enterprises and Department of Trade and Industry; 2010.

[19] Sebitosi AB, Pillay P. Renewable energy and the environment in South Africa: A way forward. Energy Policy 2008;36:3312-6.

[20] DoE. Project Design Document. Department of Energy 2010 Available from: http://www.energy.gov.za/files/esources/kyoto/kyoto_frame.html. 